\title{
TERMINOLOGY AND CONCEPTS OF CONTROL AND FUZZY LOGIC
}

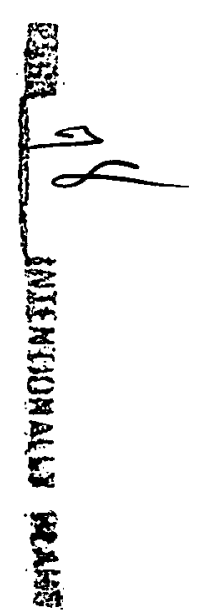

\author{
Presented at \\ A Workshop on Fuzzy Control \\ Huntington Beach, CA \\ 14 November 1990 \\ Dr. Jack Aldridge, MDSSC- SSD (Houston) \\ Dr. Robert Lea NASAJSC \\ Dr. Yashvant Jani Lincom Corp. \\ Dr. Jonathan Weiss MDSSC-SSD (Houston)
}

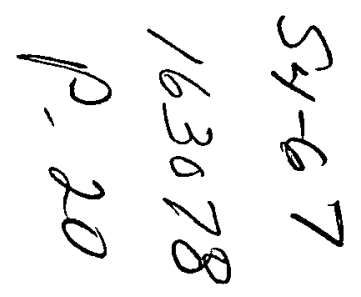




\section{PURPOSES OF THIS TALK}

- Briefly review control history - how do ideas "fit together"

- Establish terminology of control theory and fuzzy logic to promote useful discussions

- Establish basic concepts in both areas for the same purpose 


\section{CONTROL SYSTEMS}

MCDONNELL DOUGLAS

- A means by which a variable quantity or a set of variable quantities is made to conform to a prescribed norm or to vary in a prescribed way

- May be operated by electrical means, mechanical means, hydraulic means, pneumatic means, or a combination

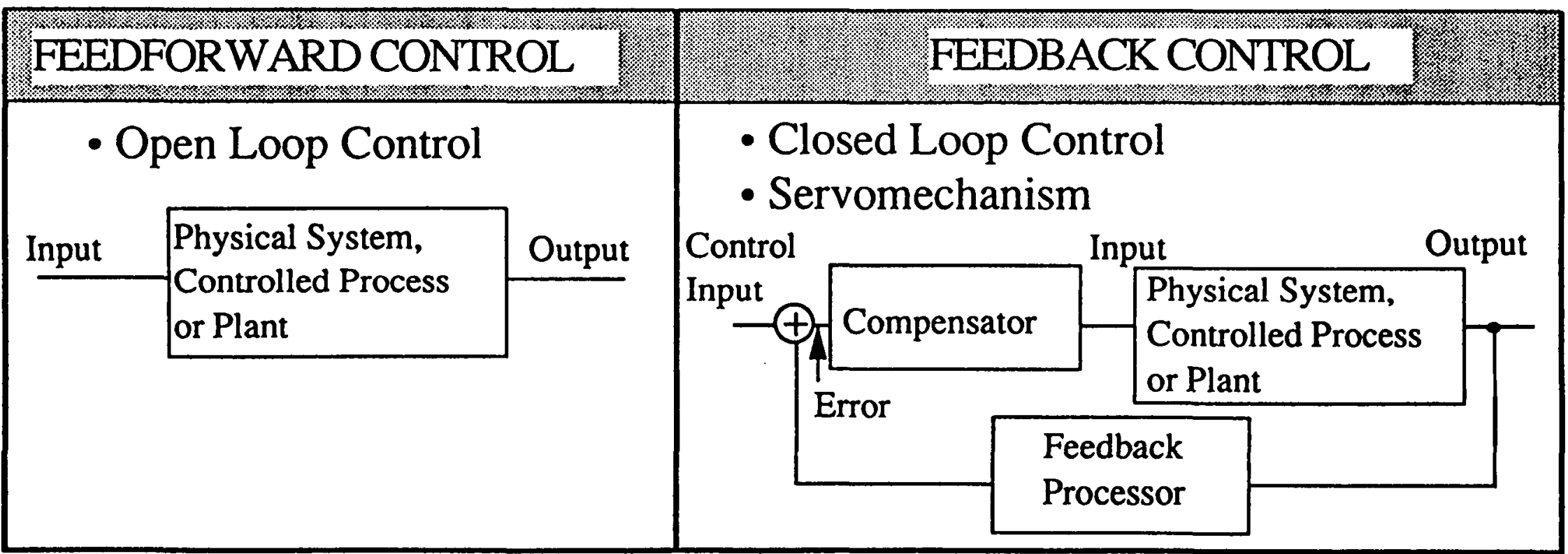




\section{CONTROL THEORY WAS FORMULATED IN THREE PHASES}

MCDONNELL DOUGLAS

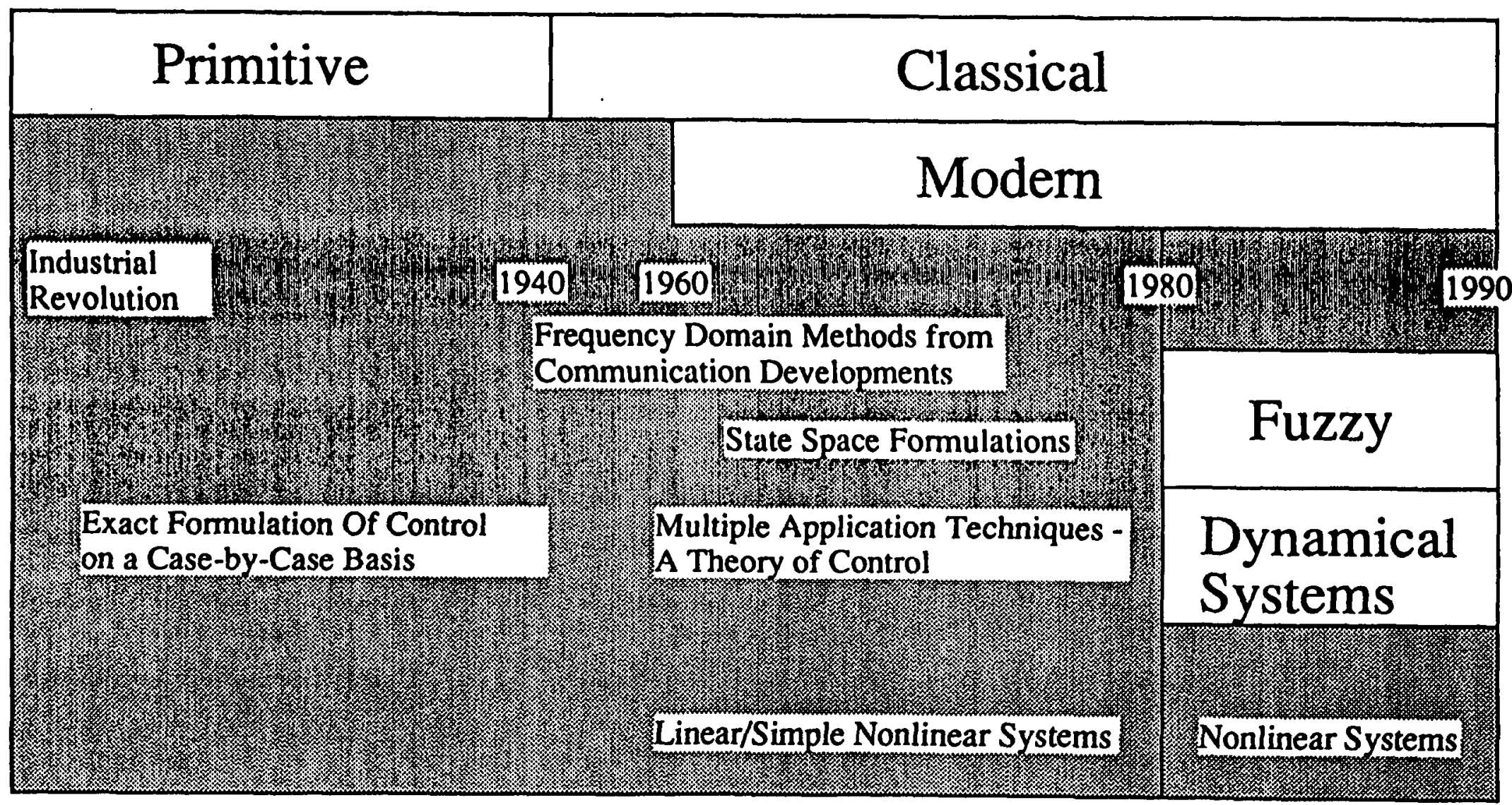




\section{ISSUES IN THE DESIGN OF A CONTROL SYSTEM}

MCDONNELL DOUGLAS

Stability and Transient Response

Response Time or Bandwidth

Observability

Controllability

Continuous or Sampled Data

Single or Multiple Control Loops

Optimizing or "Near-Optimal" Control

Fixed, Adaptive, or Learning Control 


\section{EXAMPLES: INVERTED PENDULUM}

Control Problem: Determine a control force, $f$, applied to the cart (pivot point) to keep pendulum at fixed angle

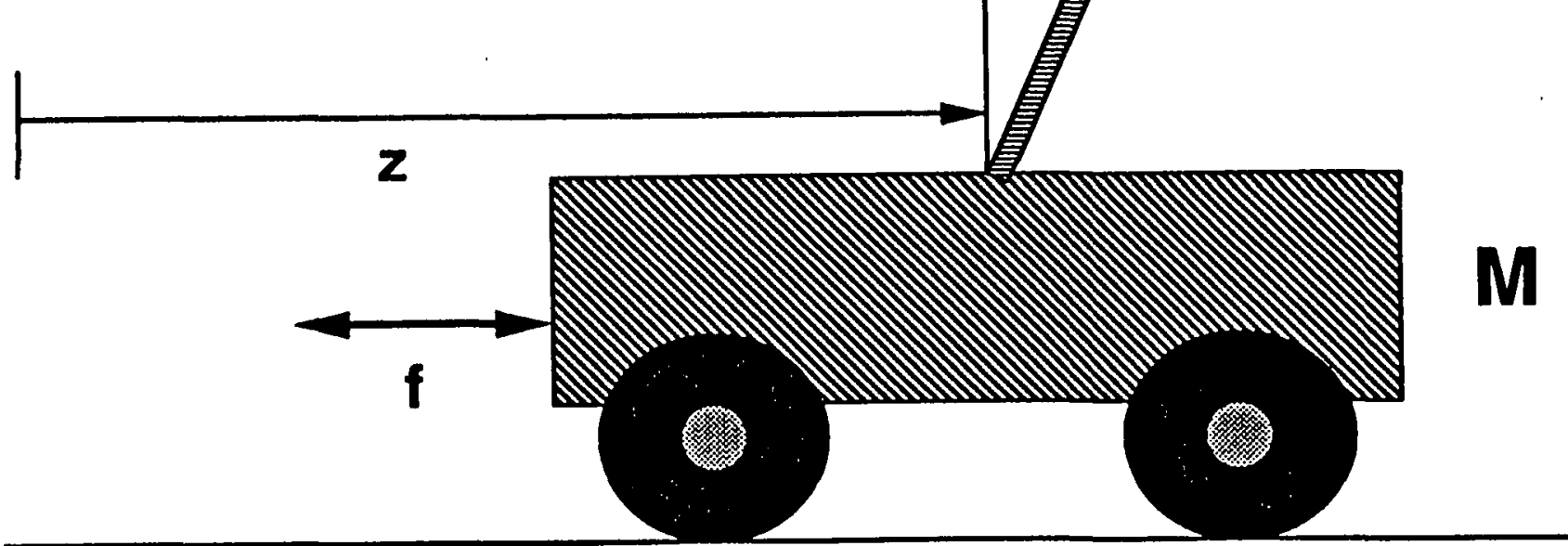




\section{STATE SPACE CONTROL FOR INVERTED PENDULUM}

Equations of Motion

$(M+m) \ddot{z}+m l \cos \theta \ddot{\theta}-m l \dot{\theta}^{2} \sin \theta=f$

$m \ell \cos \theta \ddot{z}+m \ell^{2} \ddot{\theta}-m g l \sin \theta=0$

State Space Description of Dynamical System

$$
\begin{aligned}
& \dot{z}=v \\
& \dot{v}=\frac{m l\left(\omega^{2} \sin \theta\right.}{M+m \sin ^{2} \theta}-\frac{m g \cos \theta \sin \theta}{M+m \sin ^{2} \theta}+\frac{f}{M+m \sin ^{2} \theta} \\
& \dot{\theta}=\omega \\
& \dot{\omega}=\frac{g \sin \theta(M+m)}{l\left(M+m \sin ^{2} \theta\right)}-\frac{m \omega^{2} \sin \theta}{M+m \sin ^{2} \theta} \frac{f \cos \theta}{M+m \sin 2 \theta}
\end{aligned}
$$




\section{LINEARIZED STATE SPACE}

$$
\begin{aligned}
& \dot{z}=v \\
& \dot{v}=\frac{f}{M}-\frac{m g \theta}{M} \\
& \dot{\theta}=\omega \\
& \dot{\omega}=\frac{(M+m) g \theta}{M \ell}-\frac{f}{M \ell}
\end{aligned}
$$




\section{DYNAMICAL SYSTEM MODEL FOR INVERTED PENDULUM ON A CART}

MCDONNELL DOUGLAS

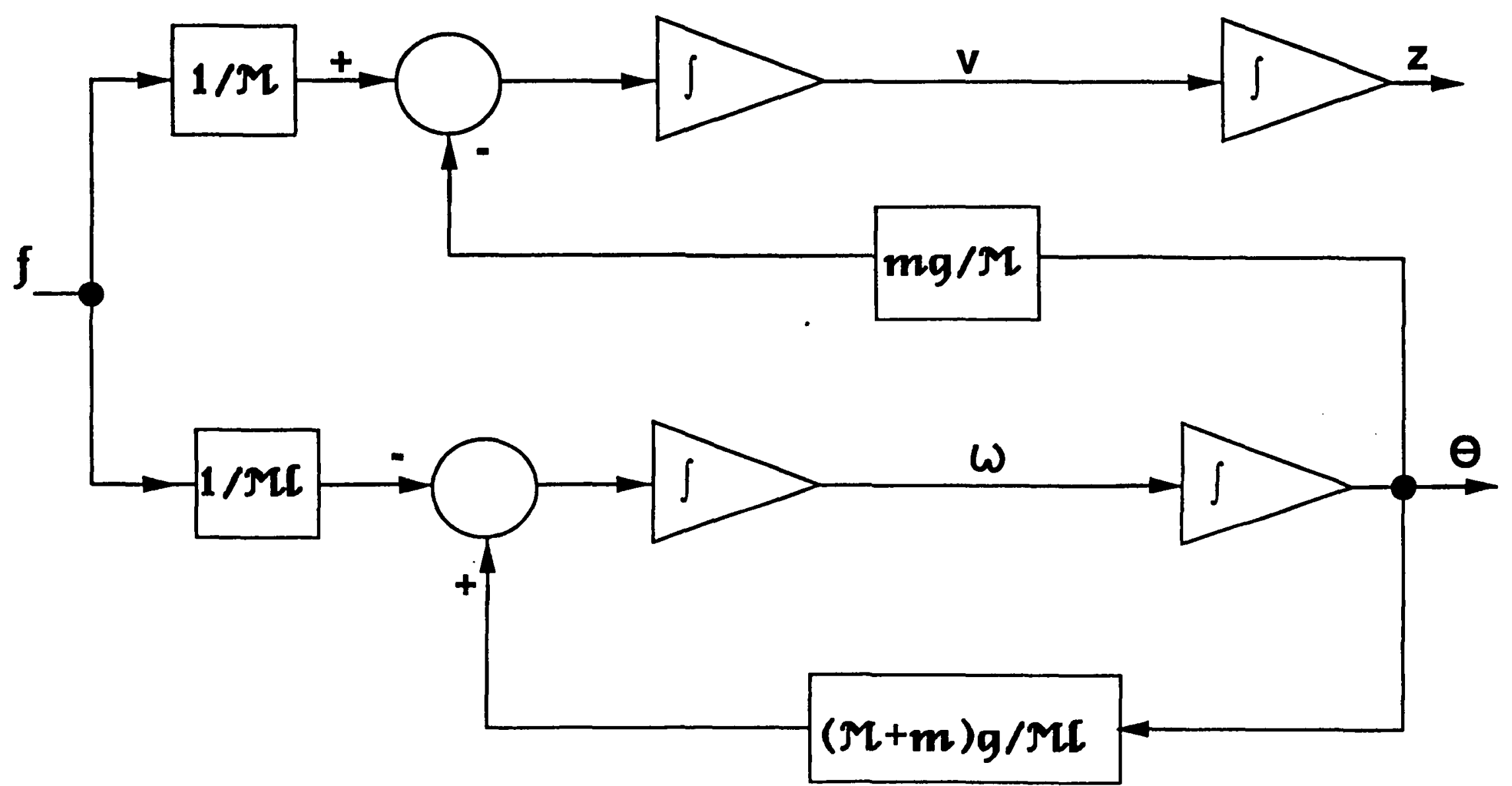




\section{PROPORTIONAL-INTEGRAL-DERIVATIVE (PID) CONTROLLER}

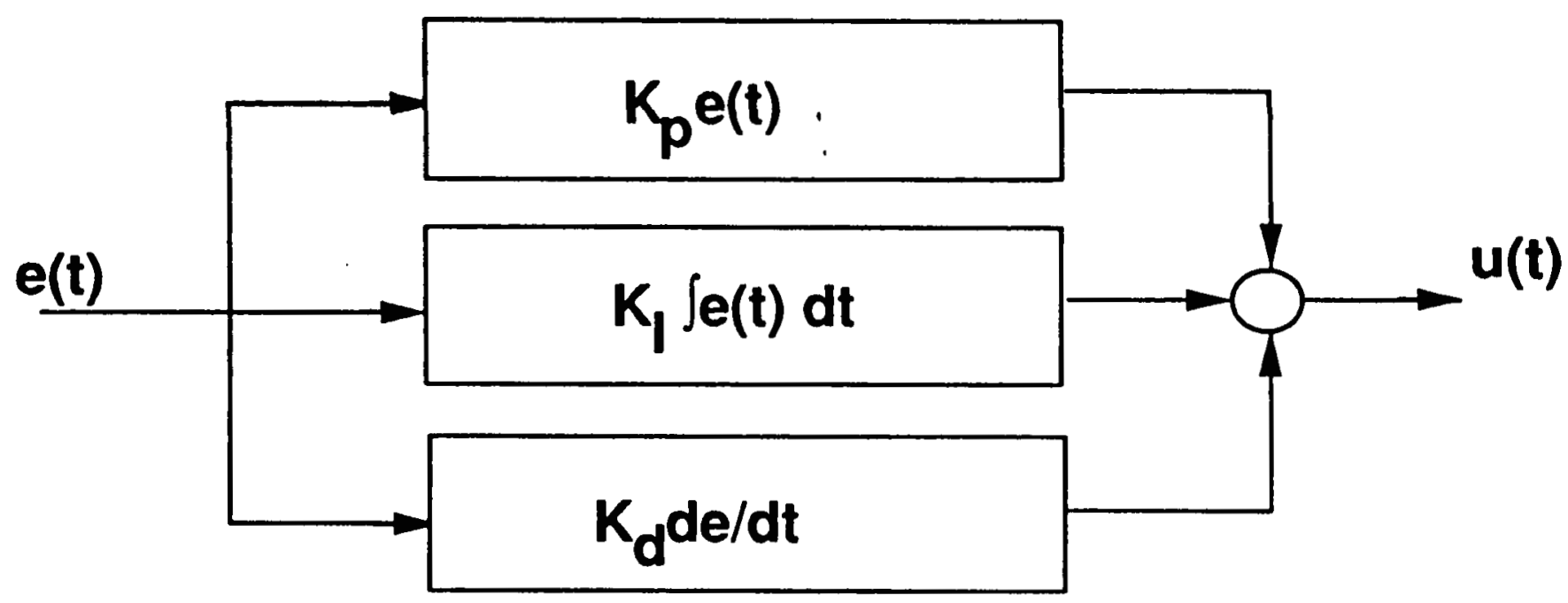

Proportional component reduces error Integral component reduces steady state offset Derivative component anticipates and reduces overshoots 


\section{ADVANTAGES OF USING CONVENTIONAL CONTROL}

- Technology is well established

- Many control problems are well approximated by linear plants or can be handled with adaptive systems that perturb controller : parameters

- Technology is mathematically based allowing general properties of controllers to be explored by a theoretical approach 


\section{PROBLEMS WITH STATE SPACE CONTROL?}

MCDONNELL DOUGLAS

- Model building stage is elaborate, iterative, error-prone, and time consuming

- A performance index that can be used for optimization must be formulated

- Actuators may be nonlinear

- Complex equipment may be poorly described by systems of differential equations but may be best described from experimental data or heuristics (rules of thumb or experience).

- Heuristics may be part of the operating procedure and may be based on mental models other than the physical models 


\section{FUZZY CONTROLLER OVERVIEW}

MCDONNELL DOUGLAS

Fuzzy

Set

Membership

Functions

IF...THEN... Rules

IF $\mathrm{X} 1$ is $\mathrm{ZO}$

THEN $u 1$ is NS

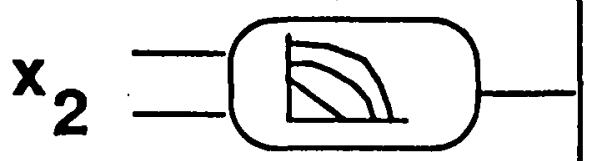

IF $x 1$ is NS

THEN u1 is PB

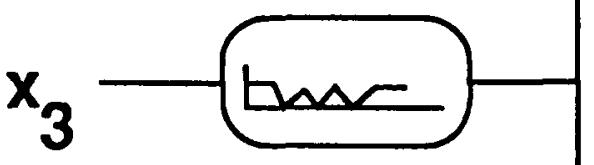

IF $x 2$ is Small AND $x 4$ is Large

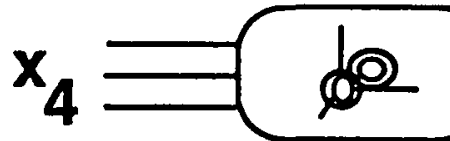

THEN $\mathrm{u} 2$ is NS

Sensor Inputs Fuzzifier

Rule Processing

Defuzzifier

Control

DESIGNER-SUPPLIED

INFORMATION IS UNDERLINED

Defuzzifier

Techniques

MAX

Centroid

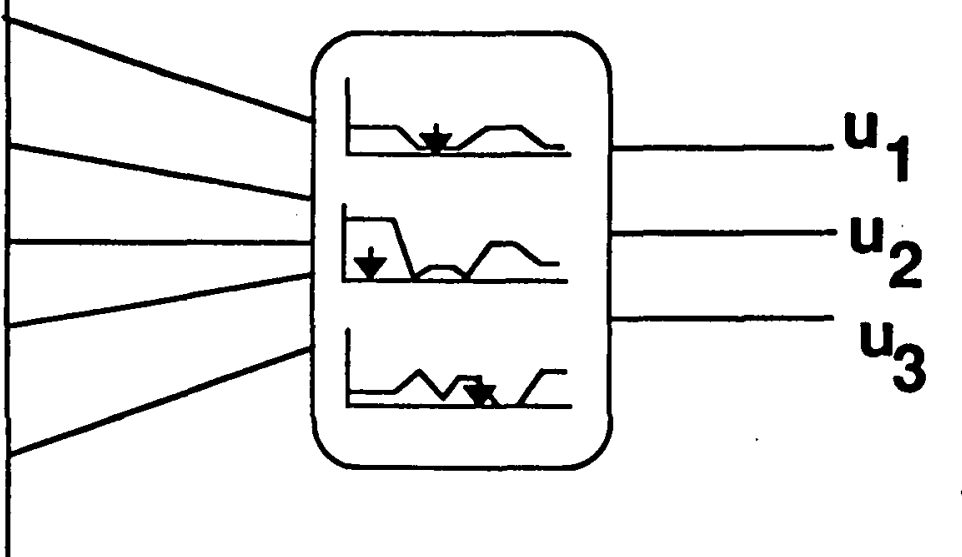

Outputs 


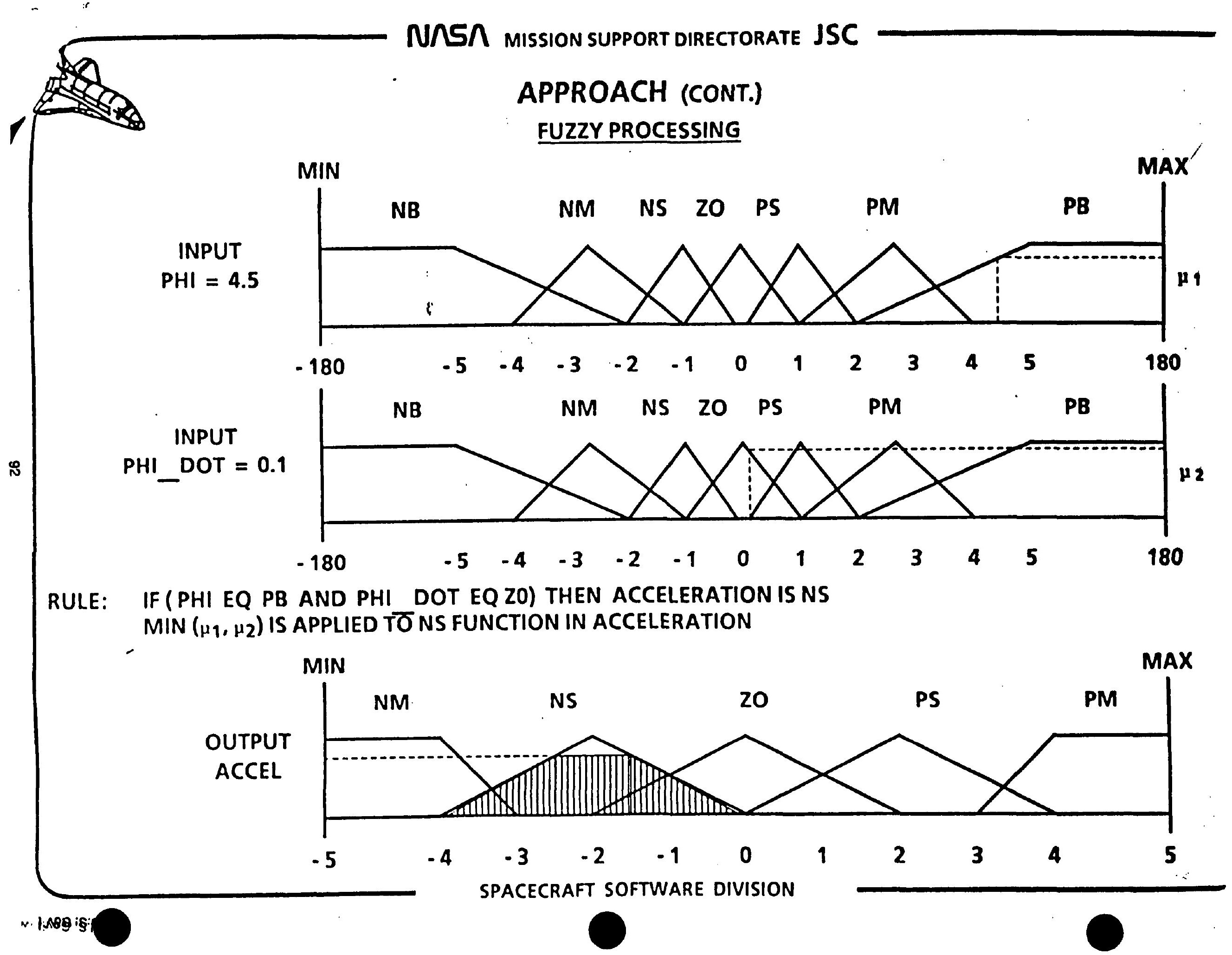




\section{RULE BASE FOR FORCE ON INVERTED PENDULUM CART}

MCDONNELL DOUGLAS

Angle

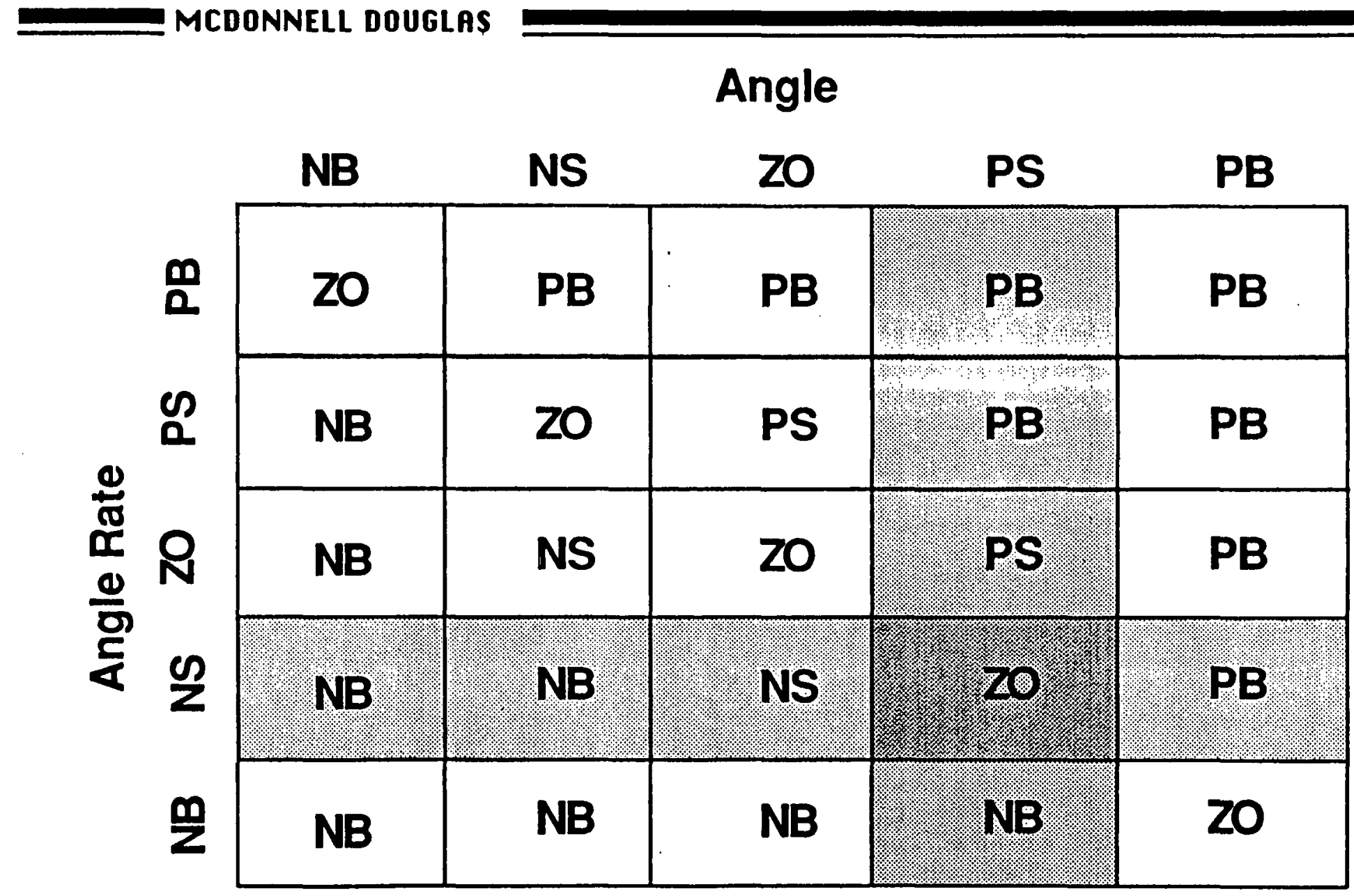

Example Rule: IF Angle is PS AND Angle Rate is NS THEN Force is ZO 
MISSION SUPPORT DIRECTORATE JSC

\section{APPROACH (CONT.)}

FUZZY PROCESSING

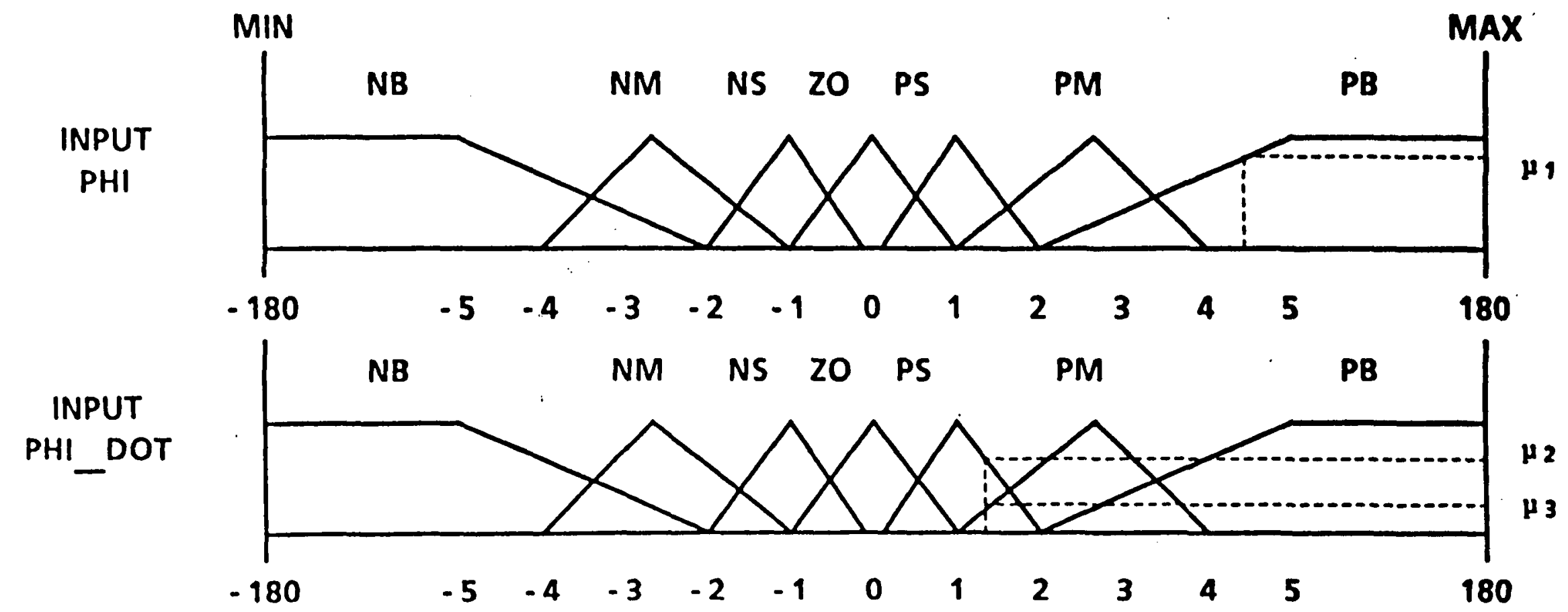

TWO RULES FIRE: 1. IF PHIIS PB AND PHI DOT IS PS THEN ACCEL IS NS

2. IF PHIIS PB AND PHIDDOT IS PM THEN ACCEL IS NM

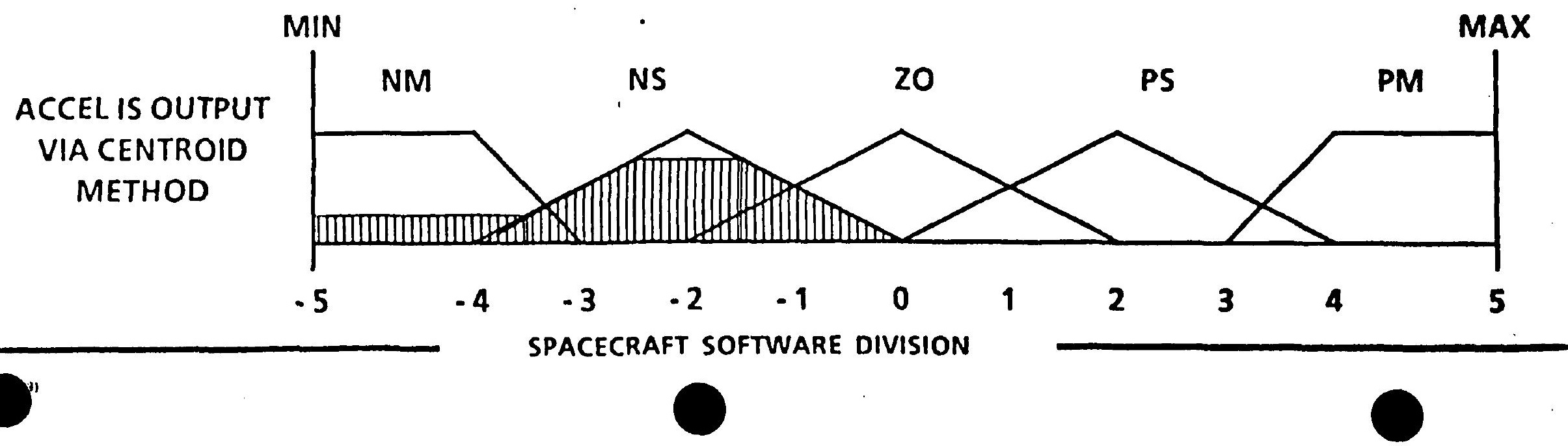




\section{FUZZY RULE PROCESSING}

MCDONNELL DOUGLAS

USE MAXIMUM FOR LOGICAL OR

IF ... THEN $u$ is NS .3

IF ... THEN $u$ is $Z O$

IF ... THEN $u$ is PS .1

IF ... THEN $u$ is PB .3

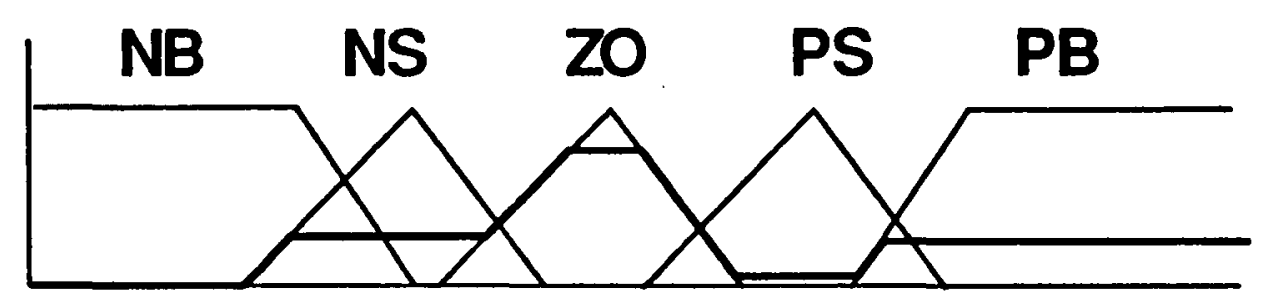

USE MINIMUM FOR LOGICAL AND

Rule: IF $x 1$ is NS AND $x 2$ is ZO

THEN $u$ is PS

Facts:

$x 1$ is NS 0.2

$\mathrm{X} 2$ is $\mathrm{ZO} 0.8 \Rightarrow \mathrm{u}$ is PS 0.2
Other options exist for combining logical connectives but these preserve all results from normal set theory except exclusion law: A AND NOT $A=\varnothing$ 


\section{DEFUZZIFICATION}

MCDONNELL DOUGLAS

MAX Procedure

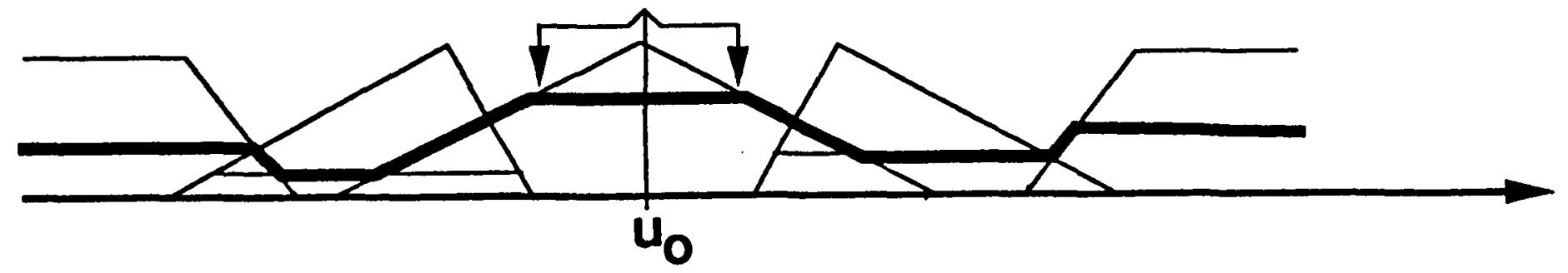

\& Centroid Procedure

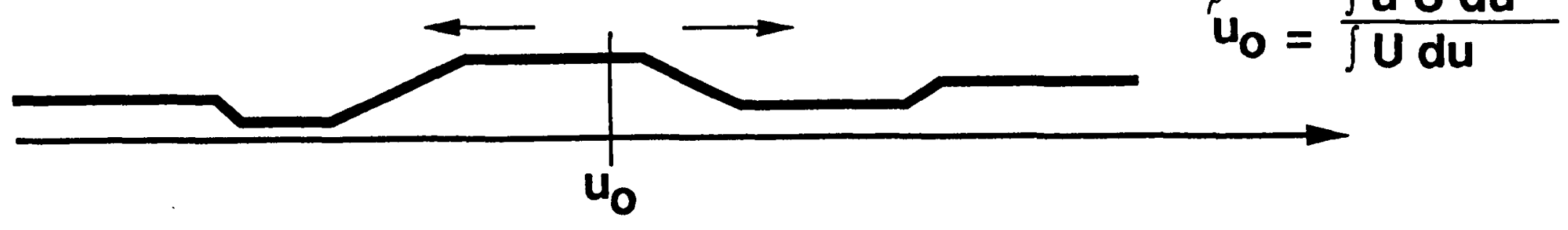

Indexed MAX or Centroid Procedure

Same as above except use only points $>$ threshold value 


\section{FUZZY CONTROLLER ADVANTAGES}

- Can exploit heuristic knowledge of operation of controlled systems. This includes physical intuition.

- Can accomodate small changes in system or controller parameters. This are the aging effect and nonlinear effects such as flexibility of beams

- Experience has been that these techniques seem to handle nonlinearity well

- Tools have been developed to assist in studying and building fuzzy controllers in short times

- The development of fuzzy chips has provided computationally capable platforms on which to build the controller, independent of general purpose computers used for spacecraft control 


\section{REMAINING ISSUES FOR FUZZY CONTROL}

- Issues such as stability, observability, and controllability raised in servomechanism and state space control are not yet in comparable state of development. This may limit initial applicability to noncritical applications

- Definition of membership functions is arbitrary and controller designer dependent.

- Procedures for selecting membership functions and defuzzifier options are not firmly established in the control community

- There are limited sources for fuzzy control chips 